\title{
La información estatal e internacional en El Porvenir de Canarias (1852-1853)
}

Julio Antonio Yanes Mesa

\section{(2) OpenEdition}

1 Journals

Edición electrónica

URL: https://journals.openedition.org/cher/453

DOI: $10.4000 /$ cher.453

ISSN: 2803-5992

Editor

Presses universitaires de Strasbourg

Edición impresa

Fecha de publicación: 10 junio 2021

Paginación: 49-61

ISBN: 9791034400928

ISSN: 1968-035X

\section{Referencia electrónica}

Julio Antonio Yanes Mesa, «La información estatal e internacional en El Porvenir de Canarias

(1852-1853)», reCHERches [En línea], 26 | 2021, Publicado el 15 septiembre 2021, consultado el 18 noviembre 2021. URL: http://journals.openedition.org/cher/453 ; DOI: https://doi.org/10.4000/cher 453

Tous droits réservés 


\title{
La información estatal e internacional en El Porvenir de Canarias (1852-1853)
}

\author{
Julio Antonio Yanes Mesa*
}

\section{Planteamiento y justificación de la investigación}

En los renglones que siguen, nos hemos propuesto analizar la información foránea de la prensa de las islas Canarias de mediados del siglo XIX, tanto la procedente del resto del Estado como la del extranjero, con la finalidad de detectar las vías de llegada, las fuentes, los contenidos y, como colofón, la circulación en la sociedad insular. Nuestro objeto de estudio serán los noventa y ocho números que, entre el 10 de octubre de 1852 y el 29 del mismo mes de 1853, editó El Porvenir de Canarias ${ }^{1}$, el primer periódico privado de la zona oriental del Archipiélago. Estampado inicialmente en formato reducido (14 x $22 \mathrm{~cm}$ ), con ocho páginas a dos columnas separadas por gruesos corondeles, el proyecto editorial fue tan bien acogido por el público que, tras circular con periodicidad semanal los doce primeros números, desde finales de 1852, se remozó la composición, se introdujeron corondeles ciegos y se agilizó la edición a dos veces por semana. Como toda la prensa isleña coetánea, la cabecera que nos ocupa se vio obligada a reducir su agenda informativa a los «asuntos materiales» al no poder satisfacer las altas fianzas que exigía la legislación para abordar la política (Seoane 1989: 197-199), por lo que los resultados de la investigación son extrapolables, por su representatividad, a todo el sector.

El contexto en el que circuló El Porvenir de Canarias estuvo marcado por la reciente división, seis meses antes de su irrupción en el mercado, de la provincia de Canarias en dos subgobiernos y, en coincidencia con la edición del primer

* Julio Antonio Yanes Mesa, Universidad de La Laguna, ORCID: 0000-0003-20619268, <jayanes@ull.edu.es>.

1 La colección completa se conserva en la hemeroteca de El Museo Canario de Las Palmas de Gran Canaria, donde hemos consultado exhaustivamente, página a página, todos los ejemplares editados. 
número, y la entrada en vigor del real decreto de puertos francos, que habría de marcar un antes y un después en la historia del Archipiélago (Bourgón 1982). En esa coyuntura de cambio, a una primera etapa alejada de la más mínima controversia con la prensa tinerfeña por las reformas introducidas en el organigrama administrativo de la región sucedió, desde el número 64 de 2 de julio de 1853 , otra en la que se enfrascó en una dura polémica ${ }^{2}$ que habría de desembocar en la reunificación de la provincia con capital única en Santa Cruz de Tenerife (Yanes 2003: 130-135). El fracaso de El Porvenir de Canarias en su empeño de consolidar la división provincial hace explicable que, a pesar de estar respaldado por la clase dominante de su isla, pusiera el punto final a su trayectoria a poco de celebrar su primer aniversario (Yanes 2019: 29-120). Dos personajes tan relevantes en la vida insular como el político y abogado Antonio López Botas (1818-1888) y el médico y escritor Domingo J. Navarro (1803-1896) (Saavedra 1972: 5), a los que luego sustituyó el reconocido notario e historiador Agustín Millares Torres (1826-1896)³ , se sucedieron en la dirección de la notable publicación.

\section{Los cauces y los soportes de la información extra isleña}

En los tiempos de El Porvenir de Canarias, para trasladar información a distancia en el Archipiélago, todavía se necesitaba un soporte material o el desplazamiento de una persona, toda vez que el amarre del cable telegráfico submarino con Cádiz, que habría de liberar el mecanismo comunicativo de tales ataduras, se haría de rogar hasta el año 1883 (Pérez González 1997). En consecuencia, todas las noticias ajenas a Gran Canaria que llegaban a la redacción del periódico, tanto desde las otras islas como desde la Península o el extranjero, lo hacían con los pasajeros y las mercancías que recalaban en el puerto de Las Palmas. Al margen del correo oficial, reducido a dos servicios mensuales desde Cádiz (Espasa 1978), se disponía de los enlaces ocasionales que tejían los pailebotes, bergantines, goletas, bricbarcas y, en definitiva, la tradicional navegación a vela, así como de las escalas de las navieras extranjeras, todavía muy escasas, atraídas por los crecientes envíos de cochinilla a Francia e Inglaterra. De ahí, el enorme protagonismo informativo del movimiento portuario con las salidas y las entradas de los buques, el desembarco de los

2 La pugna entre las dos islas centrales del Archipiélago, Tenerife y Gran Canaria, por hacerse con los organismos rectores de la Región, comúnmente conocida como "pleito insular», ha condicionado toda la historia contemporánea del Archipiélago, desde la invasión napoleónica de 1808 hasta la actualidad (Guimerá 1987; Millares Cantero 2004).

3 Su magna Historia General de las Islas Canarias, editada originariamente en sucesivas entregas entre 1881 y 1895 , está a disposición de los interesados, con varias colaboraciones de acreditados especialistas que extienden su contenido hasta finales del Franquismo, en los seis volúmenes resultantes editados, en 1977, por Editora Regional Canaria (Millares Torres 1977). 
artículos más diversos, los anuncios de las líneas y las travesías a vela, las reseñas de los viajeros distinguidos, etc., consumiendo gran parte de la superficie informativa de la publicación que nos ocupa.

Sobre tales premisas, las páginas de El Porvenir de Canarias han dejado testimoniadas como fuentes específicas de información foránea los periódicos, los folletos y las cartas recibidas por correo postal, las hojas volantes repartidas en los puertos por los buques de paso con informaciones interesadas y los servicios de los corresponsales que, según los números 8 y 11 de 2 y 23 de diciembre de 1852, tenía en Madrid y, los números 73 y 79 de 3 y 24 de agosto de 1853, en Cádiz. De la identidad de estos, solo estamos en disposición de desvelar la del primero, que muy bien pudo ser Felipe Massieu, un hijo de la oligarquía grancanaria que cursaba estudios universitarios en la capital del Estado, quien se atribuyera desde dicha ciudad la autoría de una serie de artículos sobre «Administración» que, según salió a relucir en el número 37 de 30 de marzo de 1853, habían sido acusados de un supuesto plagio. Al margen de esa colaboración, la actividad del susodicho debió reducirse al envío de periódicos y de algún otro texto original por correo postal, lo que también debió hacer el de Cádiz y un tercero, no catalogado como "corresponsal», que, según recoge el número 80 de 27 de agosto de 1853, había enviado en una ocasión informaciones «expresamente desde Granada».

\section{Los contenidos foráneos}

\section{La economía}

Si algún asunto atraía la atención de la burguesía comercial isleña era todo lo relacionado con los mercados que absorbían las exportaciones canarias, más aún en aquellos meses en los que se estaba a la espera de comprobar la eficacia de los recién instaurados puertos francos. El primer hito informativo fue la «Noticia importante» del número 17 de 19 de enero de 1853 que, sin especificar la fuente, se hizo eco de la destrucción de la cría de la cochinilla de Honduras por «un fuerte temporal», así como de la consiguiente cotización alcista del preciado colorante en el mercado internacional y de las partidas que del mismo importaba Inglaterra, incluidas las todavía testimoniales de las islas Canarias. Sin dejar de lamentar «este suceso tan desgraciado para aquel país, pero que por otra parte tanto nos favorece», el periódico empezó a ofrecer a partir de entonces la evolución de los precios de dicho producto en el mercado británico sobre la base de unas «hojas volantes» que, según se decía en el número 20 de 29 de enero de 1853, habían empezado a llegar a las Islas desde Gran Bretaña. Luego, en el número 29 de inicios de marzo, reprodujo del diario madrileño progresista El Clamor Público (1844-1864), con un mes y medio de demora, la noticia de la constitución en Madrid de la Sociedad de Agricultura, Industria y Comercio al objeto de fomentar en todo el Estado la cría de la cochinilla y del gusano de seda «trebolino». Después del verano, en los números 84 y 86 de 10 y 17 de septiembre de 1853, a poco más de un mes del cese de la publicación, 
la redacción se hacía eco de «algunas cartas» recibidas de Honduras en las que se afirmaba que la cosecha de la cochinilla del año en curso iba a ser tan escasa como la del anterior. Paralelamente, se informaba que el mayor terrateniente de la isla de Gran Canaria, el conde de la Vega Grande, ofrecía «cochinilla madre» a precios bajos y unas «escobillas» traídas de Marsella, «con las cuales se limpiaba perfectamente el nopal con una economía grande, dado que una persona podía ejecutar el trabajo de cuatro». En definitiva, con las demoras propias de la época, los lectores de El Porvenir de Canarias estuvieron al tanto de los avatares internacionales que propiciaron el despegue del corto ciclo expansivo de la exportación de la cochinilla, toda vez que su acelerado desarrollo se desmoronó, súbita e irreversiblemente, a las dos décadas escasas (Macías 1990: 239-258).

$\mathrm{Al}$ igual que le sucediera al nuevo renglón del sector exterior de la economía canaria, la cochinilla, el tradicional del vino, que arrastraba una profunda crisis desde finales del siglo XVII (Bethencourt 1991), también recibió noticias foráneas que, sin especificar la fuente, hablaban de quebrantos de la competencia en el mercado internacional. Pero las informaciones, que se referían a la isla de Madeira, no suscitaron expectativa alguna porque se trataba de una enfermedad, el oidium tuckeri, que amenazaba a todas las plantaciones vitícolas, incluidas las isleñas. A partir del número 33 de 16 de marzo de 1853, el bisemanario grancanario empezó a ocuparse, sin especificar tampoco de dónde tomaba los datos, de los estragos de la plaga que, a partir de un foco en Londres, estaba asolando desde 1845 los viñedos de los países de Europa occidental (Piqueras 2010). Junto a la ruina de los cultivos, en los números comprendidos entre el 34 de 19 de marzo y el 38 de 2 de abril de 1853, se publicó en sucesivas entregas «la memoria que respecto de la materia ha escrito D. Jacinto Montells y Nadal, catedrático de Historia natural del Instituto de Málaga» ${ }^{4}$. Tres meses más tarde, en el número 61 de 22 de junio de 1853, el periódico ofrecía a sus lectores otro documento de las mismas características, que, firmado por el boticario malagueño Pablo Prolongo ${ }^{5}$, se ocupaba del estado del viñedo en la citada provincia andaluza. Por consiguiente, El Porvenir de Canarias no solo dio a conocer la evolución del azote que, por entonces, sufrieron las plantaciones de vid europeas sino, también, las medidas preventivas que debían tomar los agricultores isleños para evitar su propagación en las Islas.

Las informaciones foráneas referidas al otro renglón de la economía canaria que, junto con el de la cochinilla, se mostró más dinámico a raíz del establecimiento de los puertos francos, la salazón del bacalao, fueron propiciadas por los primeros envíos de muestras del renovado producto al mercado

4 En concreto, se trata del folleto Memoria sobre la enfermedad de la vid de esta provincia, editado en la Imprenta y Librería de B. Vilá, Málaga, en 1852, con 31 páginas.

5 Dos reseñas sobre el quehacer de Pablo Prolongo García, representativo del sector en la época, tiene el lector a su disposición en: Pérez de Rubín (2011: 239-242) y Garrido y Pérez de Rubín (2011: 242-245). 
peninsular. Los orígenes de la reactivación del sector databan de inicios de febrero de 1853, cuando el periódico dio a conocer las actividades desarrolladas al respecto por el comisionado regio Manuel Rafael de Vargas en colaboración con el conde de la Vega Grande, propietario de las salinas, el armador de buques Gerónimo Navarro y otros miembros de la burguesía local (Martínez Milán 1992: 24-26). Luego, en ediciones sucesivas, al tiempo que los lectores recibían toda suerte de detalles sobre la evolución del proyecto, en el número 26 de 19 de febrero de 1853, podían leer una serie de cifras tomadas de la prensa peninsular sobre el volumen comercializado por países tan diversos como Dinamarca, Inglaterra, Suecia, Francia o Portugal, que ponían de relieve las posibilidades el sector. El bisemanario grancanario confirmó sus buenos augurios cuando, en la primera página del número 84 de 10 de septiembre de 1853, se regocijaba de la valoración que las primeras muestras de las salazones enviadas desde Canarias habían merecido a la prensa madrileña. Así, mientras La España decía tras «examinar varios ejemplares... [que]... nada dejan de desear respecto a su blancura, conservación, tamaño y vista», El Heraldo añadía que su calidad «no hemos visto generalmente en el pescado procedente de los mares del Norte». Todo ello, junto con el sostenido crecimiento de la exportación de la cochinilla, evidencia que los coetáneos fueron plenamente conscientes, desde un principio, del cambio de coyuntura que, tras un primer medio siglo desolador, trajo el establecimiento de los puertos francos a la sociedad canaria ${ }^{6}$.

\section{La actualidad}

Bajo los titulares «Noticias Nacionales» o «Noticias de la Península», El Porvenir de Canarias ofrecía resúmenes muy sucintos de hechos que, a escala estatal, habían sido difundidos por los últimos ejemplares de prensa española recibidos por la redacción. Los contenidos extraídos no siempre eran originales porque muchas veces habían sido reproducidos de otras cabeceras, por lo que el espacio cronológico referido, además de retardado, tenía una amplitud de varios días. El Contribuyente de Cádiz, El Heraldo (1842-1854) de Madrid y La Correspondencia Autógrafa (1848-1859), este también de la capital del Estado, fueron las fuentes más utilizadas en la etapa inicial. Por su parte, la vertiente internacional, servida como «Correo Extranjero» o «Noticias Extranjeras», era un batiburrillo de acontecimientos más heterogéneo y de mucha mayor amplitud cronológica en el que el protagonismo principal correspondió, en coherencia con su honda repercusión en el viejo continente, la «cuestión de Oriente», que, por entonces, estaba en los prolegómenos de la guerra de Crimea (1853-1856). Estos textos solían aparecer compartimentados y separados por unas escuetas y diminutas referencias al país correspondiente: Inglaterra, Francia, Prusia (a

6 El denominador común de los restantes textos que, en relación con la economía insular, reprodujo el periódico grancanario de la prensa foránea, caso del referido a la producción de «caoutchouc (caucho) o goma elástica», en el número 33 de 16 de marzo de 1853 sin especificar la fuente, fue el ansia de incorporar nuevos productos al sector isleño de exportación. 
veces, Alemania), Rusia, Turquía, Grecia, «reino Lombardo-Véneto-Milán» (a veces, Italia), Portugal, Bélgica, Suiza, Estados Unidos, China o «India inglesa»; $\mathrm{y}$, en alguna ocasión, venían acompañados al final del paginado por unas «Noticias del último correo».

Relevante por la cantidad, variedad y calidad de los títulos aludidos en sus informaciones fue la relación de los periódicos extranjeros utilizados como fuente, aunque a todos ellos se accediera, evidentemente, a través de las páginas de las publicaciones peninsulares que, previamente, se habían hecho eco de tales informaciones. Así, desde diarios históricos tan señeros como el británico The Times (1785), el francés La Presse de Émile de Girardin (1802-1881) o el estadounidense The New York Tribune de Horace Greeley (1811-1872), a otros tan marginales en el contexto internacional como L'Akhbar de Argel ${ }^{7}$, aparece mencionada una veintena larga de periódicos de las procedencias más diversas en las páginas de la publicación grancanaria. A título ilustrativo podemos añadir los británicos The Morning Post (1772-1937) y el semanario The Economist (1843); los italianos La Gaceta de Milán y La Gaceta de Trieste; el francés, fundado en 1828 por los inmigrantes de tal nacionalidad en Nueva York, Le Courrier des États-Unis; los también franceses Le Moniteur Universel, Patrie y Phare de la Loire, este publicado en Nantes entre 1852 y 1944; y otros muchos que, por su irrelevancia o porque las cabeceras están reproducidas de manera incompleta o incorrecta, no estamos en disposición de poder precisar, así como los que quedaron en el anonimato detrás de expresiones tales como «dice un periódico».

Con relación a las fechas de los acontecimientos referidos, estas informaciones llegaban a los lectores con una demora que podríamos cifrar entre la decena de días, en el mejor de los casos, y las varias semanas, hasta, incluso, rebasar el mes. En el caso de las noticias nacionales, ilustrativas de ambos extremos fueron la que, en el número 23 de 9 de febrero de 1853, daba cuenta de hechos divulgados por «la Correspondencia [Autógrafa] (1848-1859) de Madrid el 17 de enero último», esto es, unas tres semanas atrás; y, en el polo opuesto, aquella otra que, en el número 36 de 26 de marzo de 1853, decía que «por el vapor Rianzares, llegado ayer a este puerto, hemos recibido noticias de la península que alcanzan hasta el 16 de este mes», es decir, con solo diez días de demora. Dadas las precarias comunicaciones interinsulares de la época, las informaciones de Lanzarote llegaban a menudo con un desfase más pronunciado que muchas de la Península, tal y como ilustra el número 8 de 2 de diciembre de 1852, cuando se publicaron unos hechos que el corresponsal en dicha isla había firmado el 16 de noviembre, esto es, con más de dos semanas de retraso. Por razones obvias, el problema se agudizaba con la información internacional, toda vez que esta ya sobrellevaba una demora de varios días en los periódicos peninsulares de los que eran extractadas por los redactores de la publicación grancanaria. A título

7 La relevancia de L'Akhbar en la Argelia de la época está puesta de relieve en Vilar (1989: 374). 
ilustrativo, en el número 41 de 13 de abril de 1853, «leemos en el semanario británico The Economist la siguiente noticia de París con fecha 17 de marzo»; y en el 42 de 16 de abril, "por la vía de los Estados Unidos hemos recibido noticias de La Habana que alcanzan hasta el 22 del pasado [...] de un periódico de Nueva York». Estas demoras, por lo demás, iban acordes con el día a día de los lectores, algunos de los cuales estaban suscritos a cabeceras peninsulares, cuyos ejemplares tardaban unos diez días en llegar a la Isla.

Desde los meses estivales, cuando la publicación entró en controversia con la prensa tinerfeña por la cuestión provincial, las noticias internacionales giraron aún más en torno a la cuestión de Oriente. Las transcripciones de «los periódicos de la península», en el número 73 de 3 de agosto de 1853, de la circular del conde Karl Robert Nesselrode (1780-1862) y otras proclamas y hechos trascendentales, a poco más de dos meses del estallido de la guerra de Crimea, revelan que los lectores grancanarios estaban al tanto de lo que sucedía en el viejo continente. Las cabeceras citadas con anterioridad, y las que salieron a relucir ahora como The Morning Herald (1780-1869), Morning's Chronicle (1769-1865), Daily Whig de San Francisco, Pester Lloyd de Budapest, Le Constitutionnel (1815-1914) de París, Deutsche Wolksballer, así como aquellas otras de las que solo se cita la ciudad editora, desde Colonia a Hong Kong, figuran en esta etapa como fuentes de unos contenidos que llegaban a través de varios intermediarios. Los trasvases de estas informaciones de unos periódicos a otros quedan ilustrados en el número 75 de 10 de agosto de 1853: "por el vapor Humboldt, que entró el 15 [de julio] en el puerto de El Havre [Normandía, Francia], procedente de Nueva York, de donde salió el 2 [de julio], se han recibido noticias de los Estados Unidos» que, en el mejor de los casos, a la vista de las fechas citadas, databan de un mes y medio atrás. En cuanto a la actualidad estatal, el problema se atenuaba notablemente porque la intermediación se solía reducir, aunque no siempre, a la cabecera recibida en la Isla, de la que se resumía el texto, caso de las informaciones referidas a las Cortes, que los periódicos madrileños solían tomar del diario de las sesiones de la Cámara de los Diputados. Junto a los títulos citados con anterioridad, a los que debía estar suscrita la redacción para disponer en todo momento de fuentes de información, los más utilizados en estos meses finales fueron La Época (1849-1936), El Clamor Público (1844-1864), El Diario Español (1852-1933), El Tribuno (1853-1855), La España (1848-1868) y La Nación (1849-1856), así como el Diario de la Marina (1832-1960) de La Habana, editado en la todavía colonia española de Cuba (Seoane 1989: 330-336).

\section{El entretenimiento}

En contraposición a las secciones citadas, en las que los breves traían la actualidad estatal e internacional, la titulada «Variedades», de las páginas centrales, ofrecía relatos extensos en varias entregas sobre curiosidades diversas. Así, entre los números 26 y 28 de 19 y 26 de febrero de 1853, la redacción reprodujo de El Contribuyente de Cádiz un relato sobre la boda de Napoleón III (1808-1873) con la española Eugenia de Montijo (1826-1920), que tanto interés 
despertó en la España de la época, a las tres semanas de su celebración. Luego, en los números 36 y 37 de 26 y 30 de marzo de 1853, era la soprano escandinava Jenny Lind (1820-1887), «la célebre prima donna en la Ópera Real Sueca, llamada por todos los periódicos el ruiseñor del norte», la que atraía la atención del bisemanario grancanario merced a un artículo publicado originariamente en «una revista francesa». En el número 38 de 2 de abril de 1853, otra publicación de la misma nacionalidad, Gazette des beaux-arts, era la fuente primigenia de los detalles ofrecidos sobre el estado en el que se encontraba por entonces la tumba de Napoleón, cuyas cenizas había repatriado en 1840 el monarca Luis Felipe I (1773-1850). En el número 50 de 14 de mayo de 1853, de «un periódico canadiense», la redacción transcribió un texto sobre "el falso Luis XVII», un individuo que se hacía pasar en los Estados Unidos por el hijo de los monarcas franceses guillotinados en la Revolución de 1789, Luis XVI (1754-1793) y María Antonieta (1755-1793), «la más torpe que hayan inventado jamás los fabricantes de mentiras». En esta sección, en el número 44 de 23 de abril de 1853, también se ofrecieron sendas reseñas biográficas, «como las publica un periódico extranjero», del recién elegido presidente de los Estados Unidos, Franklin Pierce (1804-1869), y de su fugaz vicepresidente William R. King (1786-1853); y en el número 58 de 11 de junio de 1853, el fragmento de una carta escrita en California que desmontaba «el mito de los buscadores de oro».

En esta sección de entretenimiento también quedaron reflejados, sin especificarse la procedencia de los datos, dos hechos históricos coetáneos tan relevantes como, en el número 58 de 11 de junio de 1853, la conocida a posteriori como la Rebelión Taiping (1850-1864); y, en el número 54 de 28 de mayo de 1853, la proclama dirigida por el general mexicano Antonio López de Santa Anna (1795-1876) a sus compatriotas en las vísperas de su regreso a la presidencia de México, en este caso, con casi dos meses de demora. La publicación grancanaria también se hizo eco, haciendo referencia en el número 56 de 4 de junio de 1853 a «una revista de París», del enorme impacto en el mundo occidental de la edición en un volumen, con su inmediata traducción a un sinfín de idiomas, del folletín La cabaña del tío Tom de Harriet Beecher Stowe (1811-1896), publicado originariamente por entregas en el periódico abolicionista norteamericano The National Era a partir del 5 de junio de 1851 (Huguet 2015). Esta variopinta sección también hizo hueco a un cierto desenfado, tal y como ilustra el número 61 de 22 de junio de 1853 al informar del descubrimiento en la región francesa de Lyon de los restos de un enorme «animal antediluviano [...] de cuya desaparición debemos estar muy agradecidos, ya que uno solo de ellos bastaría para privar de alimento en pocos días a la más fértil de nuestras provincias»; y también sorpresas léxicas como, en el número 59 de 15 de junio de 1853, la expresión «un surtido tan fashionable» en un texto transcrito sobre las «Modas de París» que, bajo la firma de una tal «Carolina», hablaba del Palacio Real de Bruselas. Por su parte, la profunda vocación de Agustín Millares Torres por la Historia hace explicable la reproducción, en los números comprendidos entre el 48 y 53 de 7 y 25 de mayo de 1853, del discurso leído por el militar e historiador 
Evaristo San Miguel (1785-1862) en el acto de su recepción en la Real Academia de la Historia, así como, en el número 49 de 11 de mayo de 1853, la de las bases de los premios convocados por dicha institución bajo la firma, el 24 de abril de 1853, de su secretario, el jurista Pedro Sabau Larroya (1807-1879).

En la etapa final de El Porvenir de Canarias, en la sección «Variedades» se abordó desde el magnetismo y la luz eléctrica a las condecoraciones de la orden del Toisón de Oro, pasando por el mundo clásico, el gusano de seda, el cólera, el «Celeste Imperio de China» y el despliegue del ejército inglés en el Bósforo y los Dardanelos. Especial mención por la autoridad de sus autores en sus especialidades dentro del panorama de la época merecen, del número 68 de 20 de julio de 1853, el artículo sobre «la química aplicada a las artes» de Hipólito de la Fuente Cárcamo ${ }^{8}$, tomado de la revista El Restaurador Farmacéutico (1844-1936) de la Sociedad Farmacéutica de Socorros Mutuos de Madrid; y, del número 74 del 6 de agosto de 1853, el titulado «Higiene militar» de Anastasio Chinchilla Piqueras (1801-1867), doctor en Medicina y miembro del cuerpo médico de Sanidad Militar', del que no se cita su procedencia. Asimismo, por valerse de una novedosa estrategia comunicativa que sería catalogada por los estudiosos de las Relaciones Públicas como el prototipo del modelo del «agente de prensa» (Grunig y Hunt 2000: 81-84), destaca el texto del número 78 de 20 de agosto de 1853 sobre la mujer barbuda que, junto a otras personas con malformaciones diversas, exhibía el "celebérrimo» Phineas Barnum (1810-1891) en su circo en los Estados Unidos, cuya fuente originaria fue The Chronicle of New York. También hubo en esta sección chispazos de prensa del corazón y de sucesos, en ambos casos, sin especificarse de dónde fueron tomados los respectivos relatos. Así, el número 84 de 10 de septiembre de 1853 se ocupó de la boda de la «célebre» bailarina y actriz irlandesa Lola Montez (1821-1861) con el periodista estadounidense Patrick Hull en California; y el número 80 de 27 de agosto de 1853, de la causa seguida en la Audiencia de La Coruña contra el asesino en serie Manuel Blanco Romasanta (1809-1863), conocido como «el hombre lobo», autor confeso de una decena de asesinatos.

Los contenidos científicos también encontraron hueco en la publicación grancanaria, desde los próximos a las ciencias «duras» hasta los filosóficos, aunque unos y otros en base a fuentes de diferente índole. Del primer ramo, el periódico reprodujo de la prensa madrileña, en el número 63 de 29 de junio de 1853 , un texto sobre las posibilidades de la electricidad en el tratamiento de algunas enfermedades y, en el número 60 de 18 de junio de 1853, una "carta de Mr. Corvisart» (Bertomeu 2015) sobre los fenómenos magnéticos, tomada de «la

8 Una semblanza de Hipólito de la Fuente Cárcamo ofrece la Biblioteca Virtual de la Real Academia Nacional de Farmacia (http://bibliotecavirtual.ranf.com, consultado el 02/11/2019).

9 Con el número 1862, Anastasio Chinchilla Piqueras figura entre los académicos de número biografiados de la Real Academia Nacional de Medicina de España (https:// www.ranm.es/academicos, consultado el 02/11/2019). 
publicación médico-quirúrgica francesa Le Moniteur des Hôpitaux» (1852). De la Filosofía, sin embargo, en lugar de transcripciones de otras revistas, la redacción publicó un texto original en el número 51 de 18 de mayo de 1853 que había recibido por correo postal de un colaborador bajo el titular «Consideraciones sobre el escolasticismo y las ciencias experimentales». Tras abordar el atraso de la enseñanza de la disciplina en el Archipiélago y, en general, en España, el autor argüía que, en 1844, cuando en Francia se consideraban anticuadas las teorías de los ilustrados franceses Étienne Bonnot de Condillac (1714-1780) y Destutt de Tracy (1754-1836), ambos marcaban todavía la referencia en la recién suprimida, en 1845, Universidad Literaria de San Fernando de La Laguna. En consecuencia, añadía, la escolástica y toda la filosofía de la Edad Media, «que estaban a la orden del catolicismo con sus principios de autoridad y tradición», todavía seguían vigentes en el mundo académico del país. Tales males los atribuía al aislamiento, a la falta de comunicaciones directas de las Islas con Europa occidental, lo que hacía que «ignoremos los adelantos y progresos de las ciencias». El mismo autor, cuya identidad no hemos podido desvelar, publicaría luego, en el número 61 de 22 de junio de 1853, una "exposición razonada de las causas que en el siglo XV contribuyeron al renacimiento de las letras y de la filosofía en Europa».

\section{La publicidad}

Por entonces, como todavía estaban muy lejanos los tiempos en los que la publicidad habría de convertirse en un recurso comercial productivo para los negocios en Canarias, los anuncios, que todavía no eran una vía de ingresos para el periódico, se movían entre la información y la propaganda. De los artículos de importación anunciados, particular mención, por añadir más matices al acceso de la información del exterior al Archipiélago, merece la «Escencia de Zarzaparrilla», una mixtura de hierbas de las Antillas elaborada por el farmacéutico de Matanzas Ambrosio C. de Sauto ${ }^{10}$, que, tras levantar algunas sospechas, fue analizada, y sus resultados, que evidenciaban el fraude, se enviaron a la primera autoridad provincial y a las reputadas publicaciones madrileñas El Restaurador Farmacéutico (1844-1936) y la Revista Química. Pues bien, para replicar a estas y a otras críticas recibidas en otros lugares, el citado Ambrosio C. de Sauto publicó un artículo en el periódico cubano La Aurora de Matanzas (1828-1899) en el que glosaba las bondades de la pócima y, según se puede leer en el número 40 de 9 de abril de 1853 de la publicación que nos ocupa, remitió una "profusión de hojas volantes que ha hecho circular en esta provincia», lo que deja patente que el impacto social de la prensa canaria no se puede calibrar a la simple luz de sus reducidas tiradas y su elitismo.

$10 \mathrm{Su}$ propio creador publicó sobre ella el folleto Método curativo para el uso de la zarzaparrilla vinosa del Dr. D. Ambrosio C. de Sauto, y relación de los satisfactorios resultados obtenidos con este remedio en varias partes del mundo, Botica del Dr. Sauto, Matanzas (Cuba), 1850, 90 páginas. 
Los restantes «anuncios» y «avisos» sobre artículos de importación configuran, a modo de pinceladas sueltas, una especie de cuadro impresionista que refleja las relaciones del Archipiélago con Cuba, Inglaterra, Francia y, en menor medida, la Península, aunque circunscrito al entorno de la ciudad de Las Palmas, donde el bisemanario colocaba casi el 70\% de su tirada. En cuanto a otras vías de acceso a la información foránea, en la propia imprenta del periódico se aceptaban suscripciones para publicaciones periódicas dirigidas a segmentos de público tan concretos como La crónica de los Hospitales. Periódico oficial de la Facultad de Medicina, Cirugía y Farmacia del general de Madrid (1853-1858) o la Revista de Instrucción Primaria. También se anunciaba la venta de libros a comisión, caso de la Historia General de España, de Modesto Lafuente (fray Gerundio, 1806-1866); el Diccionario geográfico-estadístico-histórico de España $y$ de sus posesiones de Ultramar de Pascual Madoz (1806-1870); o Lágrimas: novela de costumbres contemporáneas, de Cecilia Bohl de Faber (1796-1877); así como el folleto «Tablas comparativas de las antiguas medidas de Canarias con las nuevas métricas que [...] empezarán a regir a partir de 1854».

\section{El impacto social}

Como sucediera con todos periódicos isleños de la época, la información estatal e internacional de El Porvenir de Canarias, al igual que la insular, circuló por la sociedad con una difusión mucho mayor de lo que nos puedan hacer pensar las altas tasas de analfabetismo, que rondaban el 80\% (Luxán 1988), y la desarticulación del mercado lector por las pésimas comunicaciones interiores del Archipiélago. Tal aseveración está apoyada en el testimonio legado por dos periódicos grancanarios inmediatamente posteriores al que aquí nos ocupa, El Canario (1854-1855) y El Crisol (1855-1856), a propósito de la enconada batalla dialéctica que, en aquella coyuntura marcada por la división de la provincia en los dos subgobiernos, sostenía la prensa de las dos islas centrales del Archipiélago. Nos referimos a las sucesivas entregas a los suscriptores de un informe que, a modo de folletín, generó luego el volumen titulado Compilación de los derechos y títulos de la Gran Canaria y de su Capital la ciudad de Las Palmas. Pues bien, para movilizar a toda la sociedad grancanaria detrás de las aspiraciones a la capitalidad, la propia prensa, al instar a toda la población a que accediera al documento, sacó a relucir las lecturas colectivas que proliferaban en todos los lugares de reunión de la Isla, a los que acudían los analfabetos, donde los pocos que sabían leer se encargaban de que la información llegara a todos los presentes (Yanes 2019: 149-153 y 163).

Por lo tanto, la prensa se leía en voz alta en las plazas, ventas, zapaterías y barberías, así como en las veladas familiares de las largas tarde-noches de la época en las que las alternativas de ocio brillaban por su ausencia, lo que permitía que sus contenidos llegaran a círculos que rebasaban ampliamente el de los alfabetizados. La dilación de las ediciones, toda vez que las periodicidades eran por entonces semanales o, en el mejor de los casos, bisemanales, junto a la 
ausencia de otras vías de información, debieron propiciar lecturas reiteradas que amplificaron la difusión de los textos más demandados, muchos de los cuales luego se recortaban de los paginados para que circularan, de mano en mano entre los interesados en busca de alguien que supiera leer. Como colofón, el boca a boca se encargaba de llevar lo oído al resto de la sociedad, evidentemente, con las distorsiones propias de toda transmisión oral, lo que generaba, junto con las habladurías vecinales, las cartas que se recibían por correo postal, las vivencias de los recién llegados del exterior y poco más, un corpus de temas con los que las clases populares articulaban su convivencia en los espacios de sociabilidad. Como las publicaciones peninsulares a las que estaba suscrita la minoría más ilustrada ceñían su circulación a las élites, sus contenidos debieron acentuar las diferencias discursivas existentes entre la reducida cúspide y la amplia base de aquella sociedad tan desigual.

\section{Bibliografía}

Bertomeu Sánchez J. R., 2015, Venenos, ciencia y justicia. Mateu Orfila y su epistolario (1816-1853), Alicante, Universidad de Alicante.

Bethencourt Massieu A., 1991, Canarias e Inglaterra: el comercio de vinos (16501800), Las Palmas de Gran Canaria, Cabildo Insular de Gran Canaria.

Bourgón Tinao L.P., 1982, Los puertos francos y el régimen fiscal especial de Canarias, Madrid, Instituto de Estudios de Administración Local.

Espasa Civit J.M., 1978, Historia del correo en Canarias, Las Palmas de Gran Canaria, Mancomunidad de Cabildos de Las Palmas.

Garrido Sánchez M. y Pérez de Rubín J., 2011, «Un artículo de 1880 sobre el jarabe de pinsapo elaborado en la farmacia del malagueño Pablo Prolongo García (1806-1885)», Acta Botánica Malacitana, n. ${ }^{\circ} 36$, p. 242-245, <https://riuma. uma.es>, consultado el 02/11/2019.

Grunig J. y Hunt T., 2000, Dirección de Relaciones Públicas, Barcelona, Gestión.

Guimerá Peraza M., 1987, El Pleito Insular (1808-1936), Madrid, Instituto de Estudios de Administración Local.

Huguet Santos M., 2015, Breve historia de la guerra civil de los Estados Unidos, Madrid, Ediciones Nowtilus, <https://e-archivo.uc3m.es>, consultado el 20/10/2019.

Luxán Meléndez S., 1988, «El mundo de la lectura en la ciudad de Las Palmas a mediados del siglo xIx: el papel de la prensa como intermediario entre el libro y el lector», Cuadernos de Biblioteconomía y Documentación, n. ${ }^{\circ}$ 2, p. 69-113.

Macías Hernández A., 1990, «Canarias 1830-1890: el papel de la grana en la economía isleña», Áreas. Revista de Ciencias Sociales, n. ${ }^{\circ}$ 12, p. 239-258.

Millares Cantero A., 2004, Santa Cruz dominadora. El centralismo interno y la provincia imposible en el XIX canario, Las Palmas, Real Sociedad Económica de Amigos del País de Gran Canaria. 
Millares Torres A., 1977, Historia General de las Islas Canarias, 6 volúmenes, Las Palmas de Gran Canaria, Editora Regional Canaria.

Pérez González F. P., 1997, El cable telegráfico Cádiz-Tenerife, la prensa y el pleito insular (1880-1884), Santa Cruz de Tenerife, Cabildo Insular de Tenerife.

Pérez de Rubín J., 2011, «Un expediente personal relativo al boticario Pablo Prolongo García (1806-1885) confeccionado en Málaga (1832)», Acta Botánica Malacitana, n. ${ }^{\circ}$ 36, p. 239-242, <https://riuma.uma.es>, consultado el 02/11/2019.

Piqueras Haba J., 2010, «El oídium en España: la primera gran plaga americana del viñedo. Difusión y consecuencias, 1850-1870», Scripta Nova. Revista electrónica de Geografía y Ciencias Sociales, vol. XIV, n. ${ }^{\circ} 332$, <www.ub.edu/ geocrit>, consultado el 05/10/2019.

Saavedra Rodríguez J. A., 1972, Catálogo general de publicaciones periódicas en la provincia de Las Palmas (1840-1972), memoria de licenciatura inédita, Universidad de La Laguna.

Seoane M. C., 1989, Historia del periodismo en España, 2. El siglo XIX, Madrid, Alianza Editorial, 2a reimpresión.

Vilar, J. B., 1989, Los españoles en la Argelia francesa (1830-1914), Madrid, CSIC.

Yanes Mesa J. A., 2003, Historia del Periodismo Tinerfeño, 1758-1936. Una visión periférica de la Historia del Periodismo Español, Santa Cruz de Tenerife, Centro de la Cultura Popular Canaria.

Yanes Mesa J.A., 2019, La primera división provincial en los orígenes y la consolidación del periodismo grancanario, 1852-1859, Islas Canarias, Ediciones Densura. 